"This is the peer reviewed version of the following article: MacLeay, E., Fry, M., Roche, M.A. and Montilla, T. (2020), Care planning and nonpharmacological interventions in a metropolitan inpatient dual diagnosis service: A retrospective exploratory study. Int J Mental Health Nurs, 29: 856-867., which has been published in final form at https://doi.org/10.1111/inm.12719. This article may be used for non-commercial purposes in accordance with Wiley Terms and Conditions for Self-Archiving." 


\section{Care Planning and Non-Pharmacological Interventions in a Metropolitan Inpatient Dual Diagnosis Service: A Retrospective Exploratory Study}

MacLeay, E., Fry, M., Roche, M. A., \& Montilla, T. (2020). Care Planning and Non-Pharmacological Interventions in a Metropolitan Inpatient Dual Diagnosis Service: A Retrospective Exploratory Study. International Journal of Mental Health Nursing, 29(5), 856-867. https://doi.org/10.1111/inm.12719.

\section{Abstract:}

In Australia the terms dual-diagnosis and comorbidity are commonly used, often interchangeably, to describe the experience of consumers with both mental health difficulties and difficulties with alcohol and other drug use. Consumers with comorbidity often have complex needs that require comprehensive assessment, multidisciplinary team support and trauma focused management. More information about the demographics of consumers admitted with comorbidity, and the documented assessed needs, care, and interventions provided, would provide the foundations for working towards improved quality and continuity of care. Therefore, the aim of this study was to explore the documentation of inpatient assessment, care, and interventions provided to people with comorbidity.

The research design was a retrospective exploratory study and data collection involved a 12-month health care record audit.

Forty-one records were screened, and 36 consumer health care records were identified as eligible for inclusion in the study. Most consumers $(n=34,94 \%)$ were admitted on an involuntary basis and $8(22.2 \%)$ were female. Consumers had a median length of stay of almost six months. In most health care records there was no documented evidence of care planning involvement by consumers or the multidisciplinary team. There was great variance in the delivery of non-pharmacological interventions. Most consumers did not receive trauma focused assessment or intervention, and assessment tools were often incomplete with outcome measures poorly documented.

This study has demonstrated significant gaps in consumer and multidisciplinary engagement with care planning and goal setting. There was poor documentation of comprehensive assessment and non-pharmacological interventions.

Keywords:

adult, comorbidity, dual diagnosis, mental health, substance-related disorders

Acknowledgements:

The researchers would like to acknowledge the support of managers, staff, and colleagues throughout the Mental Health Drug and Alcohol Directorate, and Northern Sydney Local Health District. The work required for the study was conducted in salaried time. Their generosity with their time in sharing their experience and knowledge was invaluable. 


\section{Introduction}

The World Health Organisation (2019) recognises that mental health disorders and substance use disorders present a major burden of disease globally, with $14 \%$ of the global burden of disease attributable to mental ill health, neurological and substance use disorders (World Health Organisation mhGAP Action Programme, 2008). As with all consumers seeking help from mental health services, consumers experiencing comorbidity have complex needs. Compared to those with a single mental health or substance use disorder, people who experience simultaneous mental health and substance use disorders have more severe symptoms, more suicidal thoughts and behaviours, poorer social, interpersonal and general functioning, reduced quality of life, significantly shorter life expectancy, and more negative treatment outcomes (Deady et al., 2013; Marel et al., 2016; K. Mills, Marel, Madden, \& Teesson, 2019; Torrens, Mestre-Pinto, \& Domingo-Salvany, 2016). These consumers experience significant difficulty navigating the health care system (Edward \& Robins, 2012), complicated by wide variation in terminology and definitions (Canaway \& Merkes, 2010; Guest \& Holland, 2011; Marel et al., 2016; Montanari, Baldacchino, Pasinetti, Thanki, \& Vicente, 2013; Tonigan, Pearson, Magill, \& Hagler, 2018). In light of these inconsistencies, in this paper the term comorbidity will be used to describe the concurrence of mental health and substance use disorders, and specialist services for this group will be referred to as dual-diagnosis services. Perhaps consequent to the variation in terminology and definitions, there is no consensus regarding treatment approaches and best practice, and no international or Australian guidelines. Whilst some studies have examined the characteristics of consumers facing these challenges, there is a dearth of research into care delivery in a specialist dual-diagnosis inpatient setting, in particular consumers' needs and their translation into individual goals and recovery-oriented care plans. In addition, there is limited research into what types of non-pharmacological interventions are offered to people with comorbidity. This study will therefore describe the characteristics of consumers admitted to a specialist dual-diagnosis service, with a focus on their documented needs, care planning, and the interventions recorded.

\section{Background}

Internationally, the prevalence of comorbid substance use and mental health disorders is high. In a Danish study, Toftdahl et al. (2016) found that the prevalence of lifetime substance use disorders was $30.4 \%$ among Danish psychiatric patients ( $n=463,003)$, with the highest in patients with personality disorders $(46 \%)$, schizophrenia, schizotypal disorder, and bipolar disorder (32-37\%). A review of 39 studies commissioned by the European Monitoring Centre For Drugs and Drug Addiction (Torrens et al., 2016) identified that comorbidity was more prevalent in consumers presenting for treatment for mental health disorders across Europe than in the general population, and estimated a prevalence of around $50 \%$ in those presenting to alcohol and drug services. In India, the prevalence of comorbidity for people seeking treatment at a 'de-addiction' centre $(n=179)$ was $32.4 \%$ (Subodh, Hazari, Elwadhi, \& Basu, 2016). Hunt et al. (2016) conducted a systematic review and meta-analysis ( 78 studies, $n=65,785$ ), noting high prevalence of comorbid bipolar and substance use disorders across a combined hospital and community sample, with alcohol use disorder having the highest prevalence (30\%), cannabis use disorder (20\%), and any drug use disorder (17\%).

Similarly, in Australia a significant proportion of people experience comorbidity. Prior et al. (2017) reported that the prevalence of substance use disorders with mood and anxiety disorders in the general population was $5.1 \%$ (approximately 811,000 people). They highlighted that $19 \%$ (approximately 154,000 ) experienced substance use disorder plus at least one mental health disorder. Lai and Huang (2009) accessed New South Wales public health inpatient data $(n=1,592,156)$ and reported that of 100,209 cases with mental health or drug and alcohol diagnoses, 9,584 experienced both; a comorbidity rate of $9.6 \%$. In a review of 18 studies investigating those seeking help specifically for drug and alcohol issues in Australia (Kingston, Marel, \& Mills, 2017), the prevalence of comorbidity was between $47 \%$ and $100 \%$ (study $n$ ranged from 13 to 1105). Bright et al. (2018), undertook a 12-month medical chart audit and found the point prevalence of comorbidity among older Australians accessing the first specialist inpatient alcohol and drug service for older people was $89 \%(n=79)$. Others have identified comorbidity in $15.5 \%$ of 593 consumers that presented to a community mental health service for older adults (Searby, Maude, \& McGrath, 2016). The clinical significance of comorbidity was identified by Reilly et al. (2019) who found that $57.6 \%$ of 2,118 people admitted over a five-year period had clinically significant Health of the Nation Outcome Scale (HoNOS) scores in the drug and alcohol domain, that indicated the need for intervention or monitoring.

Despite this scope, there is little consensus on best practice in this area and no guidelines. An integrated model of service delivery, whereby treatment of both the mental health and substance use issues is undertaken concurrently, 
appears to provide the best outcomes for consumers, although formal service evaluation is limited (de Andrade, Elphinston, Quinn, Allan, \& Hides, 2019; Deady et al., 2015; Deady et al., 2013; Marel et al., 2016).

Deady et al. (2015) reviewed current models of care for consumers with comorbidity and suggested that dualdiagnosis services should focus treatment on the impairment and distress experienced by the client, rather than solely on diagnosis of primary/secondary substance use disorder; use an integrated approach incorporating psychosocial and pharmacotherapy strategies for both substance use and mental health problems; align treatment, care and psychosocial support with the best available evidence, and national and international standards; thoroughly assess all presenting conditions and manage the most severe symptoms first; use evaluated eHealth technologies to support treatment where appropriate; and prioritise good rapport to actively engage clients in treatment. However, at present there are no comprehensive guidelines that are specific to inpatient rehabilitation for comorbidity in New South Wales, Australia (where this study was undertaken) or internationally (Vitali et al., 2018). Clinicians identify individual and organisational barriers in caring for consumers with comorbidity. Edward and Munro (2009) identified issues including fragmented communication between agencies, different treatment philosophies between specialist mental health and alcohol and other drug clinicians, complexities in assessment, and variation in staff skills and qualifications. More recent clinician interviews undertaken by Groenkjaer et al. (2017) noted inconsistent collaboration between services alongside identification and access challenges, service suitability, competing policies, and funding.

Ideal integrated models of service delivery operate within a framework that emphasises that recovery is possible and defined by the individual. This incorporates consumer empowerment, collaboration with consumers' families and carers, and a person-centred approach (Australian Health Ministers' Advisory Council, 2013a; Mental Health Coordinating Council \& Adults Surviving Child Abuse, 2014). Consumer involvement in generating goals is a key component in recovery oriented practice (Australian Health Ministers' Advisory Council, 2013a). A trauma focus is also particularly important as individuals with comorbidity often have a history of having been exposed to one or more traumatic events (K. L. Mills, 2015). Trauma such as sexual and physical abuse has been linked to the development of mental health disorders, drug and alcohol disorders and with admission to mental health hospitals (Afzali, Sunderland, Batterham, Carragher, \& Slade, 2017; Bishop, Benz, \& Palm Reed, 2017; Eriksen, Shumba, Ekeberg, \& Bogstrand, 2018; Kealy \& Lee, 2018; Mergler et al., 2018). Trauma informed care recognises the impact of power differentials in service settings, maximises self-determination, supports autonomy and empowers individuals to learn about the nature of their injuries and to take responsibility in their own recovery (Mental Health Coordinating Council \& Adults Surviving Child Abuse, 2014). Recovery oriented practice is strengths-based, maximises self-determination, is person-centred, acknowledges diversity of values, addresses the social determinants of health and offers diverse multi-disciplinary input, supports families and carers, and considers the possibility of trauma in all settings. It incorporates the core principles of trauma informed care - safety, collaboration, empowerment, trustworthiness and choice (Fallot \& Harris, 2009).

Within these service frameworks, several non-pharmacological treatment approaches have been shown to improve outcomes for both the treatment of mental health disorders and substance use disorders. These include motivational interviewing, cognitive behavioural therapy, relapse prevention techniques, psychosocial self-help groups, mindfulness training, and contingency management (Center for Substance Abuse Treatment, 2013; Horsfall, Cleary, Hunt, \& Walter, 2009). Other work (Horsfall et al., 2009; Kelly et al., 2012) has added active staged interventions, case management, social skills training, modified 12 step programmes, and education and support for family and care givers. However, a Cochrane systematic review (G.E. Hunt, Siegfried, Morley, Sitharthan, \& Cleary, 2013) concluded that there was insufficient evidence for choosing the most effective of these selected psychosocial interventions, and that evidence quality varied, although also noting that in general specific psychosocial interventions were considered effective in some domains for people with comorbidity.

In order to plan service improvement for consumers with comorbidity, clarity is required regarding consumers' characteristics, their needs as identified by standardised assessment tools, and the documentation of care planning and non-pharmacological interventions. Whilst a number of studies have examined the characteristics of consumers in dual-diagnosis inpatient units (Eagle, Ma, \& Sinclair, 2019; McKee, Harris, \& Cormier, 2013; Mowbray, Ribisl, Solomon, Luke, \& Kewson, 1997), no studies were located that employed an audit of documentation to investigate the recording of these key components of care. 
Aim

The aim of this research was to examine the characteristics of consumers in a dual diagnosis service and the documented care provided to them, including their assessed need, planned care and non-pharmacological interventions.

\section{Methods}

\section{Design}

The design of this study was a retrospective exploratory health care record audit of all consumers with direct admissions to the dual-diagnosis units between 1 June 2014 and 31 May 2015 inclusive.

\section{Ethical Approval}

Ethical approval was obtained from the service's Human Research Ethics Committee (LNR/15/HAWKE/514). A waiver of individual consent for access to records was granted in accordance with National Statement on Ethical Conduct in Human Research (NHMRC, 2007), specifically the de-identification of data on extraction, protection of consumer privacy, the impracticality of tracing all consumers involved with the service up to five years prior to the audit, and the benefits of the research in this under-studied area. All electronic data were stored in password protected files and paper data were stored in a locked cupboard only accessible by the chief researcher.

Site

The study was conducted in two specialist dual diagnosis mental health inpatient units located in metropolitan Sydney, New South Wales (NSW), Australia. One unit was a 22-bed secured locked unit and the other a 20-bed open unit with accommodation split over four cottages

\section{Health care record audit}

A 12-month health care record audit (1 June 2014 to 31 May 2015 inclusive) was conducted using both paper and electronic records. The units in question transferred to the use of electronic health care records in June 2014 so it was necessary to review both paper and electronic health care records (NSW Health, 2012). Given the unit sizes an expected sample size of 35-45 was anticipated. All health care records for direct comorbid admissions to the two units were eligible for the study. Exclusion criteria included transfers back to the units from another service. Forty-one health care records were initially accessed with 36 records included in the study. Data extraction was performed by three investigators using the data collection tool described below. Data collectors and coders met regularly during the data collection and analysis phase to discuss consistency, with consensus being reached on any issues identified.

\section{Data collection tool}

The study data collection tool was developed by a panel of clinical nurse experts who were familiar with this area of work. Data collection regarding interventions was informed by a Canadian study that explored the implementation of an effective rehabilitation unit for those experiencing comorbidity (McKee et al., 2013).

Data collected included documented consumer demographics, diagnosis, substance use assessment, interventions delivered, care planning, discharge planning and disposition. Units of data were defined by the presence or absence of documentation in the health record regarding the items identified in the data collection tool. See Table 1 for summary of the areas covered by the data collection tool.

History of childhood disruption History of childhood disruption was identified by examining health care records for records of involvement in statutory care as a child, record of childhood sexual / physical abuse or neglect, or record of department of community services intervention. Any of these indicators were taken to indicate a history of childhood disruption.

\section{Interventions delivered}

Group interventions were delivered either as part of a unit-based programme, or as part of a day rehabilitation programme - consumers were assessed and allocated to these groups. The day programme was delivered in another part of the hospital campus where consumers from different units in the hospital would attend for groups. Data was collected from the healthcare records regarding attendance to both unit and the hospital day programme. Attendance was categorised into partial attendance (less than or equal to $50 \%$, mostly attended (greater than $50 \%$ but less than $80 \%$ ), or full attendance (equal to or greater than $80 \%$ ).

Type of interventions delivered were identified by searching for a predetermined list of interventions based on a Canadian study of delivery of a rehabilitation service for comorbid individuals, plus input from and panel of nursing 
experts familiar with this area. The search required the use of certain phrases to indicate that the intervention was delivered - data collectors did not further search the documented content of that session or group. Evidence of trauma focused intervention was recorded if there was a contextually appropriate documented use of certain phrases within the health care record - i.e. trauma, abuse, sexual abuse, physical abuse, emotional abuse, neglect, sexual assault, safety, risk - which on investigation indicated a trauma based assessment or intervention.

Discharge planning and disposition

Data was collected on the presence of a plan regarding discharge, and to where the individual was discharged. This was recorded against a list of options outlined in the data collection tool, the option of 'other' was also included with space to record details.

Assessment and Outcome Measures

Each health care record was also reviewed for a set of standard measures: the Health of the Nation Outcome Scale (HoNOS) the Kessler 10 (K10), and the Life Skills Profile 16 (LSP16) (New South Wales Health, 2010). The HoNOS is a twelve-item clinician rated assessment tool used to rate consumer outcomes (Wing, Curtis, \& Beevor, 1999). Scores from the HoNOS are reported as summary scores as well as scores from twelve specific domains to give an indication of areas of need. A score of two or more in any domain indicates that there may be a need for intervention. The K10 is a ten item self-report questionnaire designed to give a global measure of psychological distress (Andrews \& Slade, 2001). The LSP 16 is a measure of function and disability in adults with schizophrenia (Parker, Rosen, Trauer, \& HadziPavlovic, 2007).

\section{Substance Use Assessment}

The substance use assessment tool is part of the Mental Health Outcome and Assessment Tools suite designed to provide guidance for documentation of treatment episodes from triage to discharge. It provides a structured format for the documentation of a consumer's drug or alcohol use. It is part of the additional tools (as opposed to core tools) for use when clinically indicated (NSW Health, 2014). Completion of this tool was recorded as was information about drug and alcohol use.

Smoking

As it became clear during the study that the completion of the Substance Use Assessment tool was low, smoking status was identified from searching through the entire health care records for recorded evidence of smoking status, Missing data indicates that no record of smoking status was found.

\section{Care planning}

Information was collected on whether the care plan involved more than one discipline, how many uni-disciplinary plans were documented, and whether the goals were determined by the consumer. Consumer determination of goals was indicated by any of the following:

- the consumer's wishes were explicitly recorded in the documented care plan

- issues identified in the consumer wellness plan were recorded in the care plan

- documentation of consumer involvement in any meeting to formulate the care plan.

If any of these criteria were recorded in the health care record, then this was taken as an indicator of a consumer determined goal. Care plans were recorded as being SMART if they met the criteria of being Specific, Measurable, Achievable / attainable, Realistic, and Time-bound (Australian Commission on Safety and Quality in Health Care, 2019). The care plans of those who had a HoNOS completed on admission were examined for translation of HoNOS needs identified to the documented care plans.

Data Analysis

Descriptive analysis was undertaken using Microsoft Excel 2016. Mean, median, standard deviation, interquartile ranges, frequency or percentages were used dependent on the type of data and its distribution. Missing data varied per item and have been reported in results.

\section{Results}

Of the 41 health care records initially identified, five were excluded as they were return transfers from other services not direct admissions during the eligibility period. A total of 36 health care records were therefore included in the study. 


\section{Consumer characteristics}

Clinical and demographic characteristics of the sample are summarised in Table 2.

Reports of child sexual or physical abuse or neglect were found in $22.2 \%$ of records $(n=8)$, and a history of child community services involvement in four (11\%). A further four cases (11\%) had a history of time spent in the statutory care system. The most common secondary diagnosis was a substance-use related diagnosis ( $n=16,44 \%$ ).

\section{Characteristics of admission}

Table 3 lists the characteristics of admission. More than half ( $n=21,58 \%$ ) of admissions were from within the local health district with almost one third $(n=10,28 \%)$ from outside the health district (data were missing in 5 cases; $14 \%$ ).

\section{Assessment tools}

The Substance Use Assessment form was complete for $16(40 \%)$ records on admission. Twelve $(75 \%)$ of these records indicated that consumers were using more than one drug on admission, most often alcohol $(n=10,62.5 \%)$, tobacco $(n=8,50 \%)$, amphetamines $(n=8,50 \%)$, cannabis $(n=7,44 \%)$ or benzodiazepines $(n=3,19 \%)$. The most common substance frequency of use recorded was daily $(n=16,40 \%)$ followed by monthly or less often ( $n=13,33 \%)$. The most common route of administration was oral, which made up $44 \%(n=18)$ of the total drug routes recorded. Smoking was the next most common route $(n=15,37 \%)$, followed by inhalation $(n=3,7 \%)$ and injecting $(n=3,7 \%)$.

Current tobacco use was identified in $28(78 \%)$ consumers.

Over $80 \%$ of consumers $(n=29)$ had the results of a HoNOS assessment documented in their health care record on admission; at discharge this had fallen to just over half ( $n=17,53 \%)$. The scores from the domains of the HoNOS on admission and discharge are shown in Table 4. Also shown in Table 4 are the percentages of care plans from consumers who had a HoNOS completed on admission, that mention the needs identified from the HoNOS.

The Kessler 10 (K10) tool was completed in 28 (78\%) health care records on admission, and 16 cases (47\%) on discharge. The mean score on admission was 16.0 (SD 9.2). For those completed on discharge $(n=16)$ the mean was 13.1 (SD 5.7). The Life Skills Profile 16 was rarely ( $n=$ three, $8 \%$ ) completed on admission, although almost half ( $n=14$, $44 \%$ ) of those discharged did have a completed form.

\section{Care planning}

There was a documented care plan for $32(89 \%)$ consumers. Multidisciplinary (referred to more than one discipline) engagement was documented in $5(16 \%)$ records. Evidence of more than one uni-disciplinary care plan was found in $28(88 \%)$ of the records of which $69 \%(n=19)$ had four or more separate care plans recorded by different disciplines. Consumer generated goals were recorded for $9(25 \%)$ consumers. There was a discharge plan in $28(88 \%)$ records. None of the care plans analysed for consumers who had a HoNOS completed on admission met the criteria for a SMART care plan.

Non-pharmacological interventions

Non-pharmacological interventions encompassed individual and group activities. Table 5 shows intervention approaches offered and Table 6 outlines groups offered. Groups were provided as part of both unit based and centrally based (hospital) day programmes, with several consumers participating in both. Attendance at the unit programme was evident in $29(81 \%)$ records - partial $(n=13,45 \%)$, mostly $(n=12,41 \%)$, or full attendance $(n=4,14 \%)$. Fewer records reported attendance at the central program $(n=15,42 \%)$ indicated as partial $(n=11,73 \%)$, mostly $(n=4$, $27 \%)$, and none with full attendance recorded.

\section{Discussion}

Care planning

This study has demonstrated that care planning rarely included consumers and seldom mentioned more than one discipline. In only a quarter of the health care records was there an indication that care plan goals were consumer generated. For most consumers there was only one discipline mentioned in the care plan (nursing) and in many cases there were multiple care plans documented by individual disciplines with no apparent attempt to implement an integrated multi-disciplinary care plan. There seems to be under utilisation of the potential of the care plan to support multi-disciplinary communication (Fichtner et al., 2001). None of the care plans analysed were written in a SMART format making effective review and evaluation of these plans a difficult task. Rio, Fuller, Taylor, \& Muir-Cochrane (2019) outline how a lack of consumer engagement in the development stage can limit the scope of care plans and the role of the mental health nurse. They also suggest that weak therapeutic relationships can lead to the inability to obtain the information to create meaningful care plans. In this study care plans seemed to be informed to some 
extent by the needs identified in the HoNOS domains, however more work is recommended in exploring the process by which assessment information informs care plans.

Trauma informed care

Within the literature there is evidence that traumatic events may have commonly occurred for people with comorbidity. A Canadian study (McKee et al., 2013) found evidence of childhood abuse or neglect in $52 \%$ of those experiencing comorbidity. Further, K. L. Mills (2015) reported that more than $80 \%$ of people presenting to alcohol and other drug services reported a history of a traumatic event - most commonly physical or sexually assault. In comparison to these studies the recorded level of childhood disruption seemed low. Indeed the documentation of a trauma related intervention or assessment is low and presents the possibility of an underestimation of need in this area. Trauma informed care is identified as a key component of mental health nursing (Beckett, Holmes, Phipps, Patton, \& Molloy, 2017), and the absence of good assessment and intervention can lead to services re-traumatising individuals at worst, and compromise the therapeutic relationship and effective engagement with consumers. Trauma focused assessment tools and interventions need to be clearly completed and documented. A pathway to better implementation of trauma informed care (TIC) requires concentrated work, with XXXX stressing the importance of supportive unit environments, necessary support by hospital management XXXX, and a clear TIC philosophy informing a practical model of care Isobel. Isobel and Delgado also suggest training in communication skills to support TIC can lead to improvements in care with ongoing supervision a necessity.

Assessment tools and outcome measures

The substance use assessment form, and other assessment tools which should be used to inform care, were not regularly completed. This inconsistency could contribute significantly to staff challenges in caring for individuals with comorbidity due to unidentified and unmet need, and could consequently lead to poorer outcomes (de Crespigny, Emden, Drage, Hobby, \& Smith, 2002; Shahriyarmolki \& Meynen, 2014; Smith, 2001). Further, outcome measures were inconsistently documented, impacting the capacity of the service to evaluate its programs (Roe, Gelkopf, Gornemann, Baloush-Kleinman, \& Shadmi, 2015).

\section{Interventions}

Analysis of documented interventions did not distinguish between individual or group interventions, with the underlying therapeutic approaches used in the latter being recorded rarely. The most commonly documented intervention approach was drug-related education with only half of the consumers offered engagement in mutual aid and social skills training. Less than half of consumers were documented as receiving motivational interviewing, a third as having received relapse prevention, and less than $10 \%$ received coping skills training. Best practice regards psychosocial interventions commonly supports improved recovery and outcomes. The findings suggest that there is a need to look at increasing the capacity of the service to offer a range of evidenced interventions on a one to one or group basis.

\section{Study Limitations}

There are several limitations which need to be considered when reviewing these results. The health care record audit required the manual searching of both paper and electronic patient records and was reliant on clinicians completing documentation. The absence of documentation may not accurately reflect everyday practice. During the study period the inaccuracies in documentation and use of incorrect templates meant that evidence of documentation was hard to locate and may have been present but not available within the health care record.

There was also the possibility that interpretation may vary between individuals during data collection and analysis. Attempts were made to minimise this variation by regular meetings between investigators to discuss any difference of interpretation and to reach consensus.

This study investigates two units which comprise a dual diagnosis service in one public hospital. These results can not necessarily be generalised across other dual diagnosis services in different contexts. However the underlying audit approach of the examination of the documentation of key areas of care is recommended as a tool for practice development in other areas.

\section{Conclusion}

This study has presented the documentation characteristics of care planning for consumers in a dual diagnosis service. According to the documentation audit, consumers were infrequently and incompletely involved in the care planning process, and it was often uni-disciplinary. This suggests that further work is needed not only to explore how best to 
involve consumers, carers, and family in care planning, but also to develop the structures, processes, and enablers for greater multidisciplinary staff integration. This work is necessary if authentic engagement and trauma-informed, person-centred care is to become a reality. Staff training in writing SMART care plans that can be effectively evaluated and reviewed is recommended alongside work on electronic documentation systems to support the documentation of collaborative, multidisciplinary care planning.

The prevalence of documented trauma was less than what may be expected, indicating that it may be under-detected. However, where a history of trauma was evident there was no documented intervention in most records. From the discussion it is recommended that a comprehensive program is needed to support the implementation of TIC, perhaps using TIC as a philosophy to underpin the nursing model of care on the units (S Isobel \& Edwards, 2017). This may include a staff training needs analysis to establish a framework for the delivery of TIC training. One previous training approach which may be worth focusing on concentrates on trauma informed communication skills (S. Isobel \& Delgado, 2018).

While documentation can at times be perceived by clinicians to be onerous, for this vulnerable group, missing, incomplete or inaccurate documentation could significantly impact on the quality of care delivery, health outcomes and consumer engagement. Training in the importance of the completion and documentation of assessment and outcome measures is recommended, as is the management support to allow staff to allocate time to complete these important tasks.

Finally, the documented delivery of non-pharmacological interventions does not closely align with best available evidence and greater efforts need to be made to better align interventions and programs with evidence and identified consumer need, the development of guidelines regarding dual diagnosis rehabilitation services may help to provide a framework for the provision of evidence- based services.

\section{Relevance for clinical practice}

Health care record audits can provide feedback to units, consumers and carers about performance, quality and fidelity of the programmes. Health care record audits of vulnerable populations such as in this study can be used to identify practice gaps and opportunities for innovation. In this dual diagnosis service regular audits can support ongoing practice development projects. Repeated regular audits can show whether desired change in documentation has occurred and highlight areas for change. Detailed audits such as this one can be time consuming, however since this audit was conducted health records have transferred entirely to an electronic record with large parts of the auditing process becoming more automated. It is possible to further refine the data collection tool to concentrate on documentation of recovery-oriented practice and TIC indicators. 


\section{References}

Afzali, M. H., Sunderland, M., Batterham, P. J., Carragher, N., \& Slade, T. (2017). Trauma characteristics, post-traumatic symptoms, psychiatric disorders and suicidal behaviours: Results from the 2007 Australian National Survey of Mental Health and Wellbeing. Australian \& New Zealand Journal of Psychiatry, 51(11), 1142-1151. doi:10.1177/0004867416683815

Andrews, G., \& Slade, T. (2001). Interpreting scores on the Kessler Psychological Distress Scale (K10). Australian and New Zealand Journal of Public Health, 25(6), 494-497. doi:doi:10.1111/j.1467842X.2001.tb00310.x

Australian Commission on Safety and Quality in Health Care. (2019). Implementing the Comprehensive Care Standard: Identifying goals of care. Sydney: ACSQHC

Australian Health Ministers' Advisory Council. (2013a). A national framework for recovery-oriented mental health services: Guide for practitioners and providers. Retrieved from Canberra:

Beckett, P., Holmes, D., Phipps, M., Patton, D., \& Molloy, L. (2017). Trauma-Informed Care and Practice: Practice Improvement Strategies in an Inpatient Mental Health Ward. Journal of psychosocial nursing and mental health services, 55(10), 34-38. doi:10.3928/02793695-20170818-03

Bishop, L. S., Benz, M. B., \& Palm Reed, K. M. (2017). The impact of trauma experiences on posttraumatic stress disorder and substance use disorder symptom severity in a treatment-seeking sample. Professional Psychology: Research \& Practice, 48(6), 490-498. doi:10.1037/pro0000165

Bright, S., Walsh, K., \& Williams, C. (2018). Point Prevalence and Patterns of Mental Health Comorbidity Among People Accessing Australia's First Older Adult-Specific Alcohol and Other Drug Treatment Service. Journal of Dual Diagnosis, 14(1), 70-75. doi:10.1080/15504263.2017.1380247

Canaway, R., \& Merkes, M. (2010). Barriers to comorbidity service delivery: the complexities of dual diagnosis and the need to agree on terminology and conceptual frameworks. Australian Health Review, 34(3), 262-268. Retrieved from http://acs.hcn.com.au?acc=36422\&url=http://ovidsp.ovid.com/ovidweb.cgi?T=JS\&CSC=Y\&NEWS=N \&PAGE=fulltext\&D=medl\&AN=20797355

Center for Substance Abuse Treatment. (2013). Substance Abuse Treatment For Persons With Co-Occurring Disorders - A Treatment Improvement Protocol TIP 42 Retrieved from Rockville:

de Andrade, D., Elphinston, R. A., Quinn, C., Allan, J., \& Hides, L. (2019). The effectiveness of residential treatment services for individuals with substance use disorders: A systematic review. Drug \& Alcohol Dependence, 201, 227-235. doi:10.1016/j.drugalcdep.2019.03.031

de Crespigny, C., Emden, C., Drage, B., Hobby, C., \& Smith, S. (2002). Missed opportunities in the field: caring for clients with co-morbidity problems. Collegian, 9(3), 29-34. Retrieved from https://www.lib.uts.edu.au/goto?url=http://search.ebscohost.com/login.aspx?direct=true\&db=cin 20\&AN $=106816590 \&$ site $=$ ehost-live

Deady, M., Barrett, E. L., Mills, K. L., Kay-Lambkin, F., Haber, P., Shand, F., . . Teesson, M. (2015). Effective Models of Care for Comorbid Mental IIIness and Illicit Substance Use -An Evidence Check Review brokered by the Sax Institute (www.saxinstitute.org.au) for the NSW Mental Health Drug and Alcohol Office. Retrieved from Sydney:

Deady, M., Teesson, M., Mills, K., Kay-Lambin, F., Baker, A., Baillie, A., . . Haber, P. (2013). One Person, diverse needs: living with mental health and alcohol and drug difficulties. In (pp. 1-52): NHMRC CRE Mental Health and Substance Use.

Eagle, K., Ma, T., \& Sinclair, B. (2019). Integrated substance use rehabilitation in a secure forensic facility. Journal of Forensic Practice, 21(1), 50-60. doi:10.1108/JFP-09-2018-0037

Edward, K.-L., \& Munro, I. (2009). Nursing considerations for dual diagnosis in mental health. International Journal of Nursing Practice, 15(2), 74-79. doi:http://dx.doi.org/10.1111/i.1440-172X.2009.01731.x

Edward, K.-L., \& Robins, A. (2012). Dual diagnosis, as described by those who experience the disorder: Using the Internet as a source of data. International Journal of Mental Health Nursing, 21(6), 550559. doi:10.1111/j.1447-0349.2012.00833.x

Eriksen, T. R., Shumba, L., Ekeberg, Ø., \& Bogstrand, S. T. (2018). The association between hospital admission and substance use among trauma patients. Journal of Substance Use, 23(1), 79-85. doi:10.1080/14659891.2017.1348557

Fallot, R., \& Harris, M. (2009). Creating Cultures of Trauma Informed Care (CCTC): A self-assessment and planning protocol. Community Connections, 2(2)(2), 1-18. 
Fichtner, C. G., Hardy, D., Patel, M., Stout, C. E., Simpatico, T. A., Dove, H., . . Giffort, D. W. (2001). A selfassessment program for multidisciplinary mental health teams. Psychiatric Services, 52(10), 13521357. Retrieved from https://www.lib.uts.edu.au/goto?url=http://search.ebscohost.com/login.aspx?direct=true\&db=cin 20\&AN $=106905928 \&$ site $=$ ehost-live

Groenkjaer, M., de Crespigny, C., Liu, D., Moss, J., Cairney, I., Lee, D., . . Galletly, C. (2017). "The Chicken or the Egg": Barriers and Facilitators to Collaborative Care for People With Comorbidity in a Metropolitan Region of South Australia. Issues in Mental Health Nursing, 38(1), 18-24. doi:10.1080/01612840.2016.1233596

Guest, C., \& Holland, M. (2011). Co-existing mental health and substance use and alcohol difficulties - why do we persist with the term 'dual diagnosis' within mental health services? Advances in Dual Diagnosis, 4(4), 162-172. Retrieved from https://www.lib.uts.edu.au/goto?url=http://search.ebscohost.com/login.aspx?direct=true\&db=cin 20\&AN $=104610532 \&$ site $=$ ehost-live

Horsfall, J., Cleary, M., Hunt, G. E., \& Walter, G. (2009). Psychosocial treatments for people with cooccurring severe mental illnesses and substance use disorders (dual diagnosis): A review of empirical evidence. Harvard Review of Psychiatry, 17(1), 24-34. doi:http://dx.doi.org/10.1080/10673220902724599

Hunt, G. E., Malhi, G. S., Cleary, M., Lai, H. M. X., \& Sitharthan, T. (2016). Prevalence of comorbid bipolar and substance use disorders in clinical settings, 1990-2015: Systematic review and meta-analysis. 206, 331-349. doi:10.1016/j.jad.2016.07.011

Hunt, G. E., Siegfried, N., Morley, K., Sitharthan, T., \& Cleary, M. (2013). Psychosocial interventions for people with both severe mental illness and substance misuse. Cochrane Database of Systematic Reviews(10). doi:10.1002/14651858.CD001088.pub3

Isobel, S., \& Delgado, C. (2018). Safe and Collaborative Communication Skills: A step towards Mental Health Nurses Implementing Trauma Informed Care. Archives of Psychiatric Nursing, 32, 291-296.

Isobel, S., \& Edwards, C. (2017). Using trauma informed care as a nursing model of care in an acute inpatient mental health unit: A practice development process. International Journal of Mental Health Nursing, 26(1), 88-94. doi:10.1111/inm.12236

Kealy, D., \& Lee, E. (2018). Childhood trauma among adult clients in Canadian community mental health services: Toward a trauma-informed approach. International Journal of Mental Health, 47(4), 284297. doi:10.1080/00207411.2018.1521209

Kelly, T. M., Daley, D. C., Douaihy, A. B., Kelly, T. M., Daley, D. C., \& Douaihy, A. B. (2012). Treatment of substance abusing patients with comorbid psychiatric disorders. Addictive Behaviors, 37(1), 11-24. doi:10.1016/j.addbeh.2011.09.010

Kingston, R. E. F., Marel, C., \& Mills, K. L. (2017). A systematic review of the prevalence of comorbid mental health disorders in people presenting for substance use treatment in Australia. Drug and Alcohol Review, 36(4), 527-539. doi:10.1111/dar.12448

Lai, H. M., \& Huang, Q. R. (2009). Comorbidity of mental disorders and alcohol- and drug-use disorders: analysis of New South Wales inpatient data. Drug \& Alcohol Review, 28(3), 235-242. Retrieved from http://search.ebscohost.com/login.aspx?direct=true\&db=cin20\&AN $=104878024 \&$ site=ehost-live

Marel, C., Mills, K. L., Kingston, R., Gournay, K., Deady, M., Kay-Lambkin, F., . . Teesson, M. (2016). Guidelines on the management of co-occurring alcohol and other drug and mental health conditions in alcohol and other drug treatment settings (2nd ed.). Sydney, Australia: Centre of Research Excellence in Mental Health and Substance Use, National Drug and Alcohol Research Centre, University of New South Wales.

McKee, S. A., Harris, G. T., \& Cormier, C. A. (2013). Implementing residential integrated treatment for cooccurring disorders. Journal of Dual Diagnosis, 9(3), 249-259. doi:http://dx.doi.org/10.1080/15504263.2013.807073

Mental Health Coordinating Council, \& Adults Surviving Child Abuse. (2014). Trauma-informed care and practice - Forum report and evaluation Retrieved from Sydney:

Mergler, M., Driessen, M., Havemann-Reinecke, U., Wedekind, D., Lüdecke, C., OhImeier, M., ... Schäfer, I. (2018). Differential relationships of PTSD and childhood trauma with the course of substance use disorders. Journal of Substance Abuse Treatment, 93, 57-63. doi:10.1016/j.jsat.2018.07.010 
Mills, K., Marel, C., Madden, E., \& Teesson, M. (2019). Submission to the Australian Government Productivity Commission Mental Health Inquiry - Lessening the Burden of Comorbid Substance Use and Mental Disorders Through Evidence-Based Care: The Case for a National Minimum Qualifications Strategy. Retrieved from

Mills, K. L. (2015). The importance of providing trauma-informed care in alcohol and other drug services. Drug \& Alcohol Review, 34(3), 231-233. doi:10.1111/dar.12273

Montanari, L., Baldacchino, A., Pasinetti, M., Thanki, D., \& Vicente, J. (2013). Co-morbidity of substance use and mental disorders. What do we know on the prevalence of psychiatric comorbidity in Europe and what are the ways forward? Mental Health \& Substance Use: Dual Diagnosis, 6(2), 97-100. doi:10.1080/17523281.2013.770654

Mowbray, C. T., Ribisl, K. M., Solomon, M., Luke, D. A., \& Kewson, T. P. (1997). Characteristics of dual diagnosis patients admitted to an urban, public psychiatric hospital: an examination of individual, social, and community domains. American Journal of Drug \& Alcohol Abuse, 23(2), 309-326.

New South Wales Health. (2010). Mental Health Clinical Documentation. Sydney: NSW Health

NHMRC. (2007). National Statement on Ethical Conduct in Human Research (2007) (Updated May 2015). Canberra, Australia: National Health and Medical Research Council.

NSW Health. (2012). PD2012_069 - Health Care Records - Documentation and Management. NSW Health NSW Health. (2014). GL 2014_002 Mental Health Clinical Documentation Guidelines. Sydney

Parker, G., Rosen, A., Trauer, T., \& Hadzi-Pavlovic, D. (2007). Disability associated with mood states and comparator conditions: application of the Life Skills Profile measure of disability. Bipolar Disorders, 9(1-2), 11-15. Retrieved from https://www.lib.uts.edu.au/goto?url=http://search.ebscohost.com/login.aspx?direct=true\&db=mn h\&AN=17391345\&site=ehost-live

Prior, K., Mills, K., Ross, J., \& Teesson, M. (2017). Substance use disorders comorbid with mood and anxiety disorders in the Australian general population. Drug \& Alcohol Review, 36(3), 317-324. doi:10.1111/dar.12419

Reilly, J., McDermott, B., \& Dillon, J. (2019). Standardized drug and alcohol questions at admission to an acute adult mental health unit: clarifying the burden of dual diagnoses across a five-year period. Australasian Psychiatry, 27(3), 270-274. doi:10.1177/1039856218810161

Rio, J., Fuller, J., Taylor, K., \& Muir-Cochrane, E. (2019). A lack of therapeutic engagement and consumer input in acute inpatient care planning limits fully accountable mental health nursing practice.

International Journal of Mental Health Nursing. Retrieved from

http://acs.hcn.com.au?acc=36422\&url=http://ovidsp.ovid.com/ovidweb.cgi?T=JS\&CSC=Y\&NEWS=N \&PAGE=fulltext\&D=ovftu\&AN=00134462-900000000-99500

http://nslhd.ovidds.com/resolver/full?output=full\&?sid=OVID:ovftdb\&id=pmid:\&id=doi:10.1111\%2Finm.12 $\underline{684}$

Roe, D., Gelkopf, M., Gornemann, M. I., Baloush-Kleinman, V., \& Shadmi, E. (2015). Implementing routine outcome measurement in psychiatric rehabilitation services in Israel. International Review of Psychiatry, 27(4), 345-353. doi:10.3109/09540261.2015.1025722

Searby, A., Maude, P., \& McGrath, I. (2016). Prevalence of co-occurring alcohol and other drug use in an Australian older adult mental health service. Int J Ment Health Nurs, 25(2), 151-158. doi:10.1111/inm.12215

Shahriyarmolki, K., \& Meynen, T. (2014). Needs assessment of dual diagnosis: A cross-sectional survey using routine clinical data. Drugs: Education, Prevention \& Policy, 21(1), 43-49. doi:10.3109/09687637.2013.796910

Smith, L. C. L. (2001). Dual diagnosis: effective recognition and management of severe mental illness and substance abuse. JAAPA: Journal of the American Academy of Physician Assistants (Haymarket Media, Inc.), 14(2), 22-30. Retrieved from

https://www.lib.uts.edu.au/goto?url=http://search.ebscohost.com/login.aspx?direct=true\&db=cin 20\&AN $=107019440 \&$ site $=$ ehost-live

Subodh, B. N., Hazari, N., Elwadhi, D., \& Basu, D. (2016). Prevalence of dual diagnosis among clinic attending patients in a de-addiction centre of a tertiary care hospital. Asian Journal of Psychiatry, 25, 169-174. doi:https://dx.doi.org/10.1016/j.ajp.2016.10.020 
Toftdahl, N., Nordentoft, M., Hjorthøj, C., Toftdahl, N. G., \& Hjorthøj, C. (2016). Prevalence of substance use disorders in psychiatric patients: a nationwide Danish population-based study. Social Psychiatry \& Psychiatric Epidemiology, 51(1), 129-140. doi:10.1007/s00127-015-1104-4

Tonigan, J. S., Pearson, M. R., Magill, M., \& Hagler, K. J. (2018). AA attendance and abstinence for dually diagnosed patients: a meta-analytic review. Addiction (Abingdon, England), 113(11), 1970-1981. doi:10.1111/add.14268

Torrens, M., Mestre-Pinto, J.-I., \& Domingo-Salvany, A. (2016). Comorbidity of substance use and mental disorders in Europe. Retrieved from Portugal:

Vitali, M., Sorbo, F., Mistretta, M., Coriale, G., Messina, M. P., Alessandrini, G., . . Zavan, V. (2018). Drafting a dual diagnosis program: A tailored intervention for patients with complex clinical needs. Rivista di Psichiatria, 53(3), 149-153. doi:10.1708/2925.29417

Wing, J., Curtis, R., \& Beevor, A. (1999). Health of the Nation Outcome Scales (HoNOS): Glossary for HoNOS score sheet. British Journal of Psychiatry, 174(5), 3. doi:10.1192/bjp.174.5.432

World Health Organisation. (2019). The Thirteenth General Programme of Work 2019-2023. Retrieved from Geneva:

World Health Organisation mhGAP Action Programme. (2008). Scaling up care for mental, neurological, and substance use disorders. Retrieved from Geneva: 
- Consumer demographics

- Diagnosis(es) on admission

- Reason for admission

- Referral source

- MHA status on admission / discharge

- Date of first contact with psychiatric services

- Primary mental health issues

- Treatment aim / plan regarding AoD use

- MDT involvement

- Number of case reviews

- Representations within 12 months

- Consumer wellness plan completion on admission / discharge

- Level of care / support on admission discharge

- HoNOS score on admission / discharge

- $\quad$ K10 score on admission / discharge

- $\quad$ LSP score on admission / discharge

- Substance use assessment completion

- Primary drug or alcohol use on admission drug / route / frequency

- AOD lapse / relapse during admission

- Smoking status

- Employment status / training status

- Private medical insurance
- School Completion

- Tertiary Education

- Statutory care as child

- Evidence of childhood sexual / physical abuse or neglect

- Childhood history of department of community services involvement

- Unit interventions

- Attendance at unit programmes

- Attendance at Day Programme Area (DPA) rehabilitation programme

- Description of DPA offering

- Evidence of MDT integrated care plan

- Time to development of initial care plan

- Do needs identified at initial assessment translate into the care plan

- Consumer identified goals in care plan documented / not documented

- Number a care plan reviews

- Pathology

- $\quad$ Referral to Wellbeing Unit

- Presence of a discharge plan

- Diagnosis on discharge

- $\quad$ Length of stay

- Presence of discharge referral plan

- Discharge disposition 
TABLE 2: CLINICAL AND DEMOGRAPHIC CHARACTERISTICS OF THE SAMPLE

\begin{tabular}{|c|c|c|}
\hline$(n=36)$ & Mean (SD) & †Includes \\
\hline \multirow[t]{2}{*}{ Age in years } & $34.4(9.7)$ & paranold \\
\hline & $\mathbf{N}(\%)$ & \\
\hline Female & $8(22.2 \%)$ & schizophr \\
\hline \multicolumn{2}{|l|}{ Place of birth } & enia, \\
\hline Australia & $29(81 \%)$ & chronic \\
\hline Other & $6(16 \%)$ & schizophr \\
\hline Missing & $1(3 \%)$ & $\begin{array}{l}\text { enla, } \\
\text { psychosis }\end{array}$ \\
\hline \multicolumn{2}{|l|}{ Cultural background } & and \\
\hline Australian Caucasian & $27(75 \%)$ & manic \\
\hline Australian Aboriginal and Torres Strait Islander & $2(6 \%)$ & psychosis, \\
\hline Other & $7(19 \%)$ & - \\
\hline \multicolumn{2}{|l|}{ Education } & paranoid \\
\hline Primary school completion & $33(92 \%)$ & $\begin{array}{l}\text { schizophr } \\
\text { enia is }\end{array}$ \\
\hline Secondary school completion & $21(58 \%)$ & included \\
\hline Attendance at Technical and Further Education & $11(31 \%)$ & even \\
\hline Commenced Apprenticeship & $5(14 \%)$ & though \\
\hline Attendance at University & $2(6 \%)$ & no longer \\
\hline \multicolumn{2}{|l|}{ Number of diagnoses } & used as a \\
\hline 0 & $2(6 \%)$ & diagnosis \\
\hline 1 & $8(22 \%)$ & diagnoses \\
\hline 2 & $14(39 \%)$ & are \\
\hline 3 & $8(22 \%)$ & included \\
\hline 4 & $3(8 \%)$ & as found \\
\hline Missing & $1(3 \%)$ & in the \\
\hline \multicolumn{3}{|l|}{ Primary diagnosis $(n=33)$} \\
\hline Psychotic disordert & $19(58 \%)$ & ‡Includes \\
\hline Schizoaffective disorder & $11(33 \%)$ & poly- \\
\hline Drug induced psychosis & $2(6 \%)$ & e \\
\hline Bipolar affective disorder & $1(3 \%)$ & $\begin{array}{l}\text { Duse, } \\
\text { ubstance }\end{array}$ \\
\hline Dual diagnosis (mental health and substance use disorders) & $24(67 \%)$ & misuse \\
\hline
\end{tabular}

disorder, substance dependence, substance use disorder, substance use, substance misuse, poly-substance use disorder, substance dependence syndrome, Mental and behavioural disorders due to multiple drug use 
TABLE 3 - CHARACTERISTICS OF ADMISSION ( $\mathrm{N}=36)$

\begin{tabular}{lc}
\hline & Median (IQR) \\
\hline Length of stay (days) & $\mathbf{N}(\%)$ \\
\hline Involuntary mental health status on admission & $34(94 \%)$ \\
Involuntary community treatment order on discharge & $22(71 \%)^{\dagger}$ \\
Discharge and disposition & \\
Home & $19(61.3 \%)$ \\
Supported department of housing accommodation & $4(12.9 \%)$ \\
Transfer to another hospital & $2(6.5 \%)$ \\
Absconded & $2(6.5 \%)$ \\
Emergency accommodation & $2(6.5 \%)$ \\
Hostel & $1(3.3 \%)$ \\
Group home & $1(3.2 \%)$ \\
Not discharged in study period & 5 \\
\hline
\end{tabular}

+ Of 31 discharged 
TABLE 4: IDENTIFIED NEED FROM HONOS ON ADMISSION AND DISCHARGE

\begin{tabular}{|c|c|c|c|}
\hline & $\begin{array}{c}\text { Admission score } \geq 2 \\
n=29\end{array}$ & $\begin{array}{c}\text { Discharge score } \geq 2 \\
n=17\end{array}$ & $\begin{array}{c}\% \text { of care plans } \\
\text { with goal }\end{array}$ \\
\hline Domain & $\mathbf{N}(\%)$ & $\mathbf{N}(\%)$ & \\
\hline Problem drinking or drug taking & $20(69 \%)$ & $4(24 \%)$ & 88 \\
\hline Hallucinations or delusions & $14(48 \%)$ & $2(12 \%)$ & 40 \\
\hline $\begin{array}{l}\text { Problems with occupation and } \\
\text { activities }\end{array}$ & $12(41 \%)$ & $1(6 \%)$ & 16 \\
\hline Problems with relationships & $5(17 \%)$ & $1(6 \%)$ & 12 \\
\hline Problems with living conditions & $4(14 \%)$ & $0(0 \%)$ & 8 \\
\hline Problems with depressed mood & $3(10 \%)$ & $1(6 \%)$ & 4 \\
\hline $\begin{array}{l}\text { Problems with activities of daily } \\
\text { living }\end{array}$ & $3(10 \%)$ & $0(0 \%)$ & 16 \\
\hline Behavioural disturbance & $2(7 \%)$ & $1(6 \%)$ & 20 \\
\hline Non-accidental self-injury & $1(3 \%)$ & $0(0 \%)$ & 0 \\
\hline Physical illness or disability & $1(3 \%)$ & $0(0 \%)$ & 4 \\
\hline Cognitive problems & $0(0 \%)$ & $2(12 \%)$ & 0 \\
\hline
\end{tabular}

HoNOS score $\geq 2$ indicated clinically significant need requiring care planned intervention

$+\%$ of the care plans identified for those consumers with HoNOS completed on admission $(n=25)$ 
TABLE 5: NON-PHARMACOLOGICAL INTERVENTION APPROACHES OFFERED

\begin{tabular}{lc}
\hline & $\mathrm{N}=36$ \\
\hline Education on drug and alcohol management & $\mathrm{n}(\%)$ \\
Social skills training & $29(81 \%)$ \\
Engagement in mutual aid & $18(50 \%)$ \\
Motivational Interviewing & $18(50 \%)$ \\
Cognitive Behavioural Therapy & $16(44 \%)$ \\
Relapse prevention & $13(36 \%)$ \\
Withdrawal management & $12(33 \%)$ \\
Coping skills training & $10(28 \%)$ \\
Trauma focused intervention & $3(8 \%)$ \\
\hline
\end{tabular}


TABLE 6: GROUP INTERVENTIONS OFFERED

\begin{tabular}{|c|c|}
\hline & $\mathrm{N}=36$ \\
\hline & $\mathrm{n}(\%)$ \\
\hline D\&A group & $21(58 \%)$ \\
\hline Alcoholics Anonymous & $18(50 \%)$ \\
\hline Narcotics Anonymous & $18(50 \%)$ \\
\hline Art therapy group & $14(39 \%)$ \\
\hline Other $\uparrow$ & $12(30 \%)$ \\
\hline Cooking & $8(22 \%)$ \\
\hline Walking group & $5(14 \%)$ \\
\hline Money management group & $4(11 \%)$ \\
\hline Women's group & $4(11 \%)$ \\
\hline Consumer group & $4(11 \%)$ \\
\hline Gardening group & $3(8 \%)$ \\
\hline Healthy lifestyle programme & $3(8 \%)$ \\
\hline Social skills group & $3(8 \%)$ \\
\hline Men's group & $3(8 \%)$ \\
\hline Sports group & $3(8 \%)$ \\
\hline Music therapy group & $2(6 \%)$ \\
\hline Social group & $2(6 \%)$ \\
\hline Pottery group & $2(6 \%)$ \\
\hline Meditation group & $2(6 \%)$ \\
\hline Recreation centre group outings & $2(6 \%)$ \\
\hline Tobacco support group & $2(6 \%)$ \\
\hline Farm outing & $2(6 \%)$ \\
\hline
\end{tabular}

† includes Mind Your Mind, Construction activities, Discussion, Lifeskills, Handwriting, Work assessment, Café work, Exercise group, Hearing voice group, Shopping, Craft making, Discharge planning 